\title{
A CONEXÃO ENTRE PENSAMENTO E REALIDADE: SOBRE A TEORIA DO CONHECIMENTO NO TRACTATUS LÓGICO-PHILOSOPHICUS DE LUDWIG WITTGENSTEIN ${ }^{1}$
}

The connection between thought and reality :about the knowledge theory in the Tractatus Logico-Philosophicus by Ludwing Wittgenstein

Bortolo Valle ${ }^{2}$

\section{Resumo}

O giro lingüístico operado na Filoso fia busca repensar o lugar da Teoria do Conhecimento. É significativa a contribuição de Ludwig Wittgenstein neste empreendimento. Do Tractatus Lógico-Philosophicus, sua primeira obra, emerge uma Teoria do Conhecimento apresentada como lógica transcendental, implicando numa posição inovadora sobre a constituição fundamental da epistemologia no âmbito da tradição filosófica, pelo menos desde a modemidade. As conseqüências epistêmicas fundamentais do Tractatus residem num fundamentalismo gnoseológico e numa relativização do conhecimento a partir de uma base lingüística.

Palavras-chave: Wittgenstein, filosofia analítica, teoria do conhecimento, epistemologia, linguagem, lógica, giro lingüístico.

1 Comunicação apresentada na mesa-redonda Virada Lingüística no III Simpósio Nacional de Filosofia sobre a Natureza do Conhecimento contribuições dos séculos XIX e XX, realizado nos dia 12, 13 e 14 de maio de 2004 na PUCPR.

2 Professor do Programa de Pós-Graduação em Filosofia - Mestrado da Pontifícia Universidade Católica do Paraná. Doutor em Comunicação e Semiótica pela PUCSP. Chefe do Departamento de Propedêutica do Direito da FDC nas Faculdades Integradas Curitiba.

E-mail: btlav@uol.com.br.

Revista de Filosofia, Curitiba, v. 16 n.18, p. 139-148, jan./jun. 2004. 
Abstract

The linguistic turn applied in the philosophy tries to rethink,also,the role of knowledge theory.Being Ludwing Wittgenstein's contribution expressive in this work.From his first work,Tractatus LogicoPhilosophicus, a knowledge theory rises , shown as trancendental logic embodying a new position about the fundamental constitution of epistemological in the traditional philosophy position, at fundamental constitution of epistemology in traditional philosophy position at least since modernity.The fundamental epistemological implications of Tractatus are in a gnoseologic fundamentalism and in a knowledge relativism from a linguistic base

Keywords: Wittgenstein, analytic philosophy, knowledgetheory ,epistemology, language,logic, linguistic turn..

Wittgenstein foi aclamado por Ferrater Mora como "o gênio da desintegração"3. É reconhecida a radicalidade dos aforismas que constituem sua primeira obra: o Tractatus Lógico-Philosophicus ${ }^{4}$, to mado não como uma teoria da linguagem formal e nem somente como a exposição do critério empirista do significado elaborado para declarar sem-sentido aquilo que não pode ser verificado.

De todas as leituras que se pode fazer do Tractatus nos limitaremos a uma que trata de apresentar as relações entre o conhecimento e a linguagem, conforme anunciado pelo filósofo já no Prólogo da obra: "Este livro, pretende, pois, traçar um limite para o pensar, ou melhor não para o pensar, mas para a expressão dos pensamentos: a fim de traçar um limite para o pensar, deveríamos poder pensar os dois lados desse limite (deveríamos, portanto, poder pensar o que não pode ser pensado)" (T.L.P. Prólogo, p.131).

Traçar limites ao pensamento ou à linguagem como expressão do pensamento é a tarefa da teoria do conhecimento: tarefa que busca separar o cognoscível daquilo que está para além da cognoscibilidade, referir o impensável a partir do pensável, o indizível a partir do dizível (T.LP. 4.114, 4.115). Parece assim que a teoria do conhecimento se fun-

3 Ferrater Mora, J. Cuestiones disputadas. Revista de Ocidente, Madrid, p.180, 1995.

4 Para este trabalho utilizamos a tradução realizada por Luiz Henrique Lopes dos Santos e publicada pela editora da Universidade de São Paulo em 1994 e agora indicado como Tractatus ou T.L.P.

Revista de Filosofia, Curitiba, v. 16 n.18, p. 139-148, jan./jun. 2004. 
de com a Ontologia e mais ainda com a Metafísica, esta entendida não como o indizível, o impensável, o incognoscível, mas como o discurso que fundamenta o dizível, o pensável, o cognoscível; devendo, portanto, situar-se para além do fundamentado.

Em Notes on Logic ${ }^{5}$ o filósofo declarava: "a filosofia (...) consta de lógica e metafísica, a primeira é sua base", acrescentando em seguida: "a epistemologia é a filosofia da psicologia" (N.L., 9). Assim, uma vez que a filosofia é constituída essencialmente pela lógica e pela metafísica parece se evidenciar uma espécie de marginalidade da teoria do conhecimento e, reduzida a uma filosofia da psicologia, nada acrescentaria à filosofia, assemelhando-se em sua função a outras ciências naturais (T.LP. 4.1121). Vale recordar ainda que em outra passagem de N.L, o filósofo havia esclarecido: "A filosofia não oferece figuras da realidade, não pode nem refutar e nem confirmar as investigações científicas" (N. L 9).

Wittgenstein parece excluir explicitamente a teoria do conhecimento das partes fundamentais da Filosofia, ou seja, da Lógica e da Metafísica. Entende que ela é uma teoria dos processos cognitivos e, por sua constituição, permite a presença do psicologismo ${ }^{6}$ no seio das investigações científicas. É compreensível, então, seu radicalismo: a filosofia é lógica e metafísica, e são elas que permitem a fusão entre o pensamento e a realidade. Os processos psicológicos de conhecimento, por sua vez, são dispensáveis, secundários até. Wittgenstein parece, assim, herdar o esforço de combate ao psicologismo empreendido por autores como Husserl e principalmente por Frege.

No entanto, reconhecer a teoria do conhecimento enquanto marcada pelo psicologismo, como sendo, portanto, dispensável, não significa reconhecer que os problemas do conhecimento sejam igualmente dispensáveis e secundários. Pelo contrário, livre o psicologismo, a lógica

5 Utilizamos neste trabalho o texto apresentado no Apendix I of Noteboocks 19141916, 2nd ed. , elaborado por G. H. von Wright and G. E. M. Anscombe, eds. Oxford: Basil Blackwell. 1979. No texto referido como N.L.

6 Por Psicologismo entendemos a concepção corrente que considera a verdade como uma propriedade da crença, do juízo ou do conhecimento entendidos como estados psicológicos de um sujeito. Como conseqüência a verdade seria uma propriedade dos conteúdos cognitivos do sujeito. A verdade seria entendida como certeza ou evidencia psicológica que, como em Descartes tornou os atos psicológicos verdadeiros por meio da equação "verdadeiro (certo) = evidente". A este propósito consultar o T.L.P., 5.1363).

Revista de Filosofia, Curitiba, v. 16 n.18, p. 139-148, jan./jun. 2004. 
e a metafísica aparecem em sua dimensão mais fundamental (este também parece ter sido o empreendimento levado a termo por Kant).

O objetivo último da reflexão filosófica é a clarificação da estrutura mais geral da realidade (ontologia, metafísica) e, como a realidade nos é dada no pensamento, deixando claros os limites do pensamento cumprimos tal tarefa. Se esta clarificação acontece por meio da expressão do pensamento, ou seja, da linguagem, a filosofia (ou a metafísica) é "critica da linguagem" (T.L.P., 4.0031), mas uma crítica de natureza lógica e, portanto, epistemológica (não no sentido da teoria psicologista do conhecimento). ${ }^{7}$

Em Wittgenstein, pois, o psicologismo transforma-se em uma barreira que impede a conexão entre a epistemologia e a ontologia; a lógica, por sua natureza é a ferramenta que pode quebrar tal barreira: a lógica que desde Aristóteles é lógica do conhecimento e lógica da realidade. A Psicologia não pode pretender este privilégio uma vez que o conhecimento pode estar condicionado, ou seja, submetido a processos psicológicos, mas a realidade é indiferente a este condicionamento (a menos de que nos deixemos levar por uma espécie de subjetivismo cético).

É por isso que no Tractatus o filósofo não pretende explicar os "processos do pensamento", mas esclarecer sua estrutura lógica, levando em consideração o pano de fundo metafísico de tal estrutura. Da mesma maneira que o Positivismo Lógico pretendeu eliminar a metafísica em nome da teoria do conhecimento, o Tractatus pretende construir uma metafísica sobre a lógica, livrando-se da psicologização do problema do conhecimento.

Reconhecer no Tractatus uma teoria do conhecimento é admiti-la a partir de seu eixo fundamental, qual seja, o da conexão entre a proposição e o fato, entre a lógica e a ontologia. Podemos afirmar que o pressuposto metodológico que torna viável tal teoria do conhecimento é aquele que brota da afinidade mantida por Wittgenstein com a maneira própria de Bertrand Russell expor o papel da lógica nos Principia Mathematica (na constituição do atomismo lógico) que, para o autor do Tractatus não interessa tanto como sistema axiomático, mas como cálculo veritativo-funcional e é este o aspecto epistemologicamente importante.

7 A este respeito o próprio Wittgenstein recorda sua diferença com o trabalho de Mauthner, conforme se pode ler no T.L.P. 4.0031. 
O problema a respeito das proposições que são função de verdade de outras - e, portanto, a respeito dos pensamentos que estas proposições expressam e de sua estrutura lógica - é derivado do problema do valor de verdade das proposições elementares (Elementarsätze). Conhecido o valor de verdade destas, existe um procedimento mecânico (as tábuas de verdade, procedimento inventado pelo próprio Wittgenstein), para conhecer o valor de verdade daquelas, aplicando as operações que definem as constantes lógicas (T.LP., 5.234 e 5.2341). Assim, chegamos ao problema central da teoria do conhecimento no Tractatus, melhor dizendo, ao problema central da conexão entre conhecimento e realidade, que é o de conhecer o valor de verdade das proposições elementares: "A proposição é a expressão da concordância e discordância com as possibilidades de verdade das proposições elementares. As possibilidades de verdade das proposições elementares são as condições de verdade e falsidade das proposições. É de antemão provável que a introdução das proposições elementares seja fundamental para o entendimento de todas as outras espécies de proposição. Com efeito, o entendimento das proposições gerais depende palpavelmente do entendimento das proposições elementares” (T.L.P., 4.4, 4.41, 4.411).

Sendo mecânico o procedimento para determinar o valor de verdade das proposições complexas, o problema epistemológico fundamental se centraliza na determinação do valor de verdade das proposições elementares. Mas não é possível entendê-lo num sentido psicológico de qualquer natureza, num sentido de processos psíquicos de conhecimento. Vale recordar, também, que não importam quais sejam concretamente as proposições elementares que podem variar por diversas razões e circunstâncias; uma vez que não é uma tarefa do filósofo sua investigação.

A tarefa do filósofo e a da teoria do conhecimento, ou o problema epistemológico fundamental é: como determinar o valor de verdade das proposições que são independentes, que não são função de valor de verdade de outras proposições, ou seja, o valor de verdade das "proposições elementares". Se conseguirmos explicar como podemos conhecer o valor de verdade de uma proposição elementar será possível explicar como dispor de uma linguagem com a qual se expressa a verdade de um pensamento que se refere ao mundo.

Determinar o valor de uma proposição elementar, ou seja, de como o mundo pode verificar ou falsear nossas proposições é tarefa da

Revista de Filosofia, Curitiba, v. 16 n.18, p. 139-148, jan./jun. 2004. 
lógica e da mística, daquilo que se mostra e não se pode dizer, ou melhor, determinar os fundamentos próprios do conhecimento. É exatamente por esta razão que Wittgenstein tem consciência de que a lógica, que está na base da metafísica, não é uma mera formalidade abstrata, uma disciplina voltada apenas para a construção de cálculos formais. A lógica se interessa pela realidade conforme podemos ler nos Diários Filosóficos: "Só a realidade interessa à lógica. Isto é, as proposições só na medida em que são figuras da realidade". (D. F. 22).

Na lógica não se faz abstrações da dimensão semântica da linguagem, do caráter da sentença como figura (picture) da realidade, não se faz abstração, tampouco, em termos kantianos, de uma referência do conhecimento ao objeto, por isso lemos no Tractatus: "A lógica não é uma teoria mas um reflexo do mundo. A lógica é transcendental" ( T.LP. , 6.13).

Mesmo que, de acordo com Wittgenstein a teoria do conhecimento seja uma lógica transcendental, esta, enquanto pretende dar conta de como é possível a dimensão semântica da linguagem, sua referência ao mundo, ou da conexão entre pensamento e realidade, é ela mesma uma teoria do conhecimento.

É forçoso reconhecer o caráter dual (híbrido) dos problemas cognitivos: se a ponte entre o conhecimento e a realidade passa pela lógica, o compromisso ontológico do conhecimento e o compromisso lógico da Ontologia situam o problema do conhecimento em sua conexão com a realidade e a teoria do conhecimento em sua dimensão metafísica. Por outro lado, se a ponte é a Psicologia, os processos subjetivos do conhecer, o conhecimento se limita (se fecha) no sujeito e a realidade permanece indiferente a estes processos.

O problema do conhecimento se situa, pois, na conexão das proposições elementares como o mundo. Isto implica uma teoria piramidal ou fundamentalista do conhecimento. A base desta pirâmide é constituída por proposições elementares que são aquelas em contato imediato com o mundo.

Não se pode confundir a posição de Wittgenstein com a versão neopositivista do conhecimento, uma vez que estamos diante do problema dos enunciados básicos ou protocolares. Wittgenstein avança, posto que apresenta a teoria do conhecimento num cenário lógico-metafisico, diferente dos representantes do neopositivismo, pelo menos de alguns que, com toda sua veneração pela lógica acabam adotando ou caindo no psicologismo e falando de "constatações", de satisfações, etc.

Revista de Filosofia, Curitiba, v. 16 n.18, p. 139-148, jan./jun. 2004. 
O problema das proposições elementares não é o problema do contato do sujeito da experiência (no sentido de uma vivência) com a realidade, mas o problema da lógica do pensamento: da estrutura lógica do que é ontológico e gnoseológico. Assim, como pode ser que os "pensamentos elementares", ou as proposições elementares estejam em contato imediato com o mundo? Em termos mais esclarecedores: como se fundamenta o conhecimento na realidade e, portanto, em toda a sua dimensão, ou melhor, como é possível o conhecimento?

Embora a resposta a esta questão seja conhecida, sua interpretação não é facilmente esclarecida: a proposição está em contato com 0 mundo porque a "proposição é uma figura da realidade (Bild). A proposição é um modelo da realidade tal como a pensamos" (T.L.P., 4.01). Os elementos da proposição, ou seja, os nomes, denotam, se referem aos objetos do mundo. "Aos objetos correspondem na figura os elementos da figura" e "o nome substitui na proposição o objeto" (T.L.P., 3.13 e 3.22). A forma dos objetos, o conjunto de suas possibilidades de combinação com outros objetos (T.L.P., 2.0141), de penetrar nos fatos atômicos corresponde no plano lingüístico, com a forma da proposição: "que os elementos da figuração estejam uns para os outros de uma determinada maneira representa que as coisas assim estão umas para as outras. Essa vinculação de elementos da figuração chama-se sua estrutura; a possibilidade desta, sua forma de afiguração" (T.L.P., 2.15).

Assim, vemos a função epistemológica da lógica, a função de ponte, talvez num sentido mais aristotélico do que kantiano: a forma lógica é comum não tanto por imposição do a priori, mas porque assim o são o mundo e o pensamento. 0 fato de assim se comportarem pertence ao reino do impensável uma vez que não podemos pensar ilogicamente. $\mathrm{O}$ a priori da lógica consiste na impossibilidade de pensar ilogicamente (T.L.P., 5.4731). Wittgenstein não está se referindo ao conhecimento, mas ao pensamento mesmo; não se trata daquilo que é incognoscível, mas daquilo que é impensável. A lógica é o comum a fatos e proposições, à realidade e ao pensamento. É a essência da ontologia e da epistemologia.

Quando enunciamos, pois, uma proposição, formulamos a possibilidade de um estado de coisas; a possibilidade de que os objetos a que os nomes que integram a proposição se referem, estejam de fato combinados da mesma forma como o estão na proposição os nomes que lhes são correspondentes. Conhecer é saber se a proposição é verdadei-

Revista de Filosofia, Curitiba, v. 16 n.18, p. 139-148, jan./jun. 2004. 
ra ou falsa, saber se os fatos são tais como a proposição os figura, saber se aquela possibilidade enunciada na proposição é algo mais que possibilidade, se é um factum.

O verdadeiro problema epistemológico e ontológico é o status das proposições elementares em relação aos fatos; mais que isso: é o status inclusive de todo o empirismo. As proposições elementares sustentam o edifício de todo o conhecimento e elas compartilham a mesma forma lógica, pois a linguagem reflete 0 mundo. Tal posição poderia dar margem para pensar que Wittgenstein propõe uma linguagem perfeita, que se comporta como estrutura ontológica do mundo, abrindo caminho para uma epistemologia ingênua e dogmática.

Não parece ser esta a intenção do filósofo. A proposta Wittgensteiniana é mais metodológica: não se trata desta ou de qualquer outra linguagem, uma vez que em qualquer linguagem encontraremos proposições elementares. Buscar quais são as proposições elementares e quais são os nomes em cada linguagem é uma investigação que não corresponde nem à lógica e nem à metafísica (nem tampouco, a uma teoria do conhecimento no sentido psicologista). O que em cada linguagem sejam proposições elementares e nomes depende de convenções semânticas ou do método concreto de projeção que se utilize (Wittgenstein faz referência a metáfora de uma malha conforme T.L.P. 6.341).

Toda linguagem, ou cada sistema de descrição do universo, como afirma o autor, é uma rede que se lança sobre o mundo. Compreendemos o mundo por meio das aberturas que constituem a rede, mas as formas das aberturas dependem de nossa decisão: são nossas convenções semânticas, nosso método de projeção, que determina sua forma de sua abertura. Toda linguagem deve ter proposições elementares, porém, quais são elas é uma variável de cada linguagem.

Assim, a concepção de uma teoria do conhecimento como lógica transcendental, que situa a análise do conhecimento em um nível formal, exige uma base fundamentalista ou piramidal do conhecimento, ou seja, toda linguagem repousa sobre um conjunto de enunciados elementares o que torna difícil a tarefa de averiguar a estrutura lógica da linguagem corrente (da linguagem cotidiana conforme T.L.P., 4.002).

Wittgenstein chama de lógica prática o empreendimento para determinar quais são os fundamentos cognitivos (as proposições elementares) de qualquer linguagem ou teoria: "a aplicação da lógica decide a respeito de quais proposições elementares existem. O que vem com

Revista de Filosofia, Curitiba, v. 16 n.18, p. 139-148, jan./jun. 2004. 
a aplicação, a lógica não pode antecipar. Isto é claro: a lógica não pode colidir com sua aplicação" (T.L.P., 5.557).

Decorrem dessas considerações na teoria do conhecimento do Tractatus três níveis diversos.

1. Uma teoria sobre os processos do pensamento. Neste sentido a teoria do conhecimento não importa muito à filosofia, por sua vulnerabilidade aos elementos do psicologismo.

2. Uma teoria do conhecimento entendida como "aplicação" da lógica. Trata-se de a posteriori uma análise (uma atividade como mostra Wittgenstein) voltada para descobrir as proposições elementares, ou seja, os fundamentos do conhecimento sobre os quais se assenta uma teoria da linguagem. Mesmo que neste nível se identifique uma tarefa legítima para a filosofia e ainda que Wittgenstein tenha dedicado alguns aforismas a esta análise, nela não se detém.

3. Um nível da lógica transcendental, na realidade uma teoria do conhecimento que, ao refletir a priori a estrutura lógica da linguagem, permite que se chegue ao núcleo do que é o conhecer e sua conexão com a realidade.

Neste último nível, no Tractatus, encontramos as linhas transcendentais de todo o conhecimento e seu necessário caráter empírico sobre a base das proposições elementares e sua comparação com 0 mundo. As teses fundamentais daí decorrentes são: primeira, que o conhecimento tem uma estrutura piramidal, ou seja, tem uma base de apoio na realidade, por meio da experiência, que de tal base se constrói 0 edifício cognitivo; segunda, que todo conhecimento depende de uma referência lingüística dada.

Também o positivismo lógico chegou a este ponto de relação básica entre os enunciados (protocolos) e a realidade. No entanto, seu sustento tem uma base nitidamente psicologista e assim, seu critério deveria admitir enunciados privilegiados sustentados pela idéia de certeza. Em Wittgenstein não se trata de buscar enunciados privilegiados, mas de buscar enunciados cujo valor de verdade é independente do valor de qualquer outro enunciado. Foi esta tese que sustentou todo o atomismo lógico e marcou os fundamentos do empirismo. Wittgenstein percebe que esta tese está carregada de erros e abandona o atomismo lógico.

Revista de Filosofia, Curitiba, v. 16 n.18, p. 139-148, jan./jun. 2004. 
A dificuldade reconhecida por Wittgenstein pode ser assim descrita: em qualquer linguagem, se estiverem presentes as exigências do Tractatus é importante que haja um conjunto de proposições cujo valor de verdade deve ser estabelecido independentemente uma das outras proposições absolutamente independentes e que se conectam cada uma isoladamente com a realidade, que constituem pontos de contato absolutos (não relacionados entre si) na base da pirâmide cognitiva.

O fracasso ou limite de tal tese consiste que tal empreendimento parece impossível. Com efeito, se "p" é uma proposição elementar (por ex. Maria é bonita) então, o fato que torna "p" falsa, isto tp, nunca poderia ser positivamente descrito por outra proposição "q" e, ao contrário, de tal modo que por definição, ao não ser o valor de verdade de "p" independente do de " $q$ " nem o de " $q$ " independente do de " $p$ ", nem " $p$ " nem "q" seriam proposições elementares.

Isto acontece com qualquer par de predicados excludentes entre si referindo a um mesmo domínio de indivíduos (p. ex. solteiro e casado, bonito e feio, esquerda e direita etc.), tais parelhas não poderiam ser proposições elementares uma vez que dado um determinado predicado podem inferir-se conseqüências sobre a verdade ou falsidade de um enunciado do qual participe um outro predicado par (T.LP., 2.0232, $2.02331,2.024)$. No entanto, é claro que a linguagem trabalha sobre a descrição dos fenômenos utilizando sistema de conceitos que se excluem entre si, quer sejam conceitos opostos ou escalonados.

\section{Referências}

VALLE, Bortolo.Wittgenstein: A forma do silêncio e a forma da palavra. Curitiba: Champagnat, 2003.

WITTGENSTEIN, L Tractatus Lógico-Philosophicus. 2 ed.rev.ampliada. São Paulo: EDUSP, 1994.

.Investigações Filosóficas. Lisboa: Fund. CALOUSTE GULBENKIAN,1995.

Recebido em/ Receieved in: 16/06/2004 Aprovado em/Approved in :04/08/2004 